\title{
Analysis of Stress Distribution in Tensile Test Specimens Using Modified Versions of a Novel Gripping System
}

\author{
András Mucsi \\ Faculty of Mechanical and Safety Engineering, Óbuda University, Budapest, 1081, Népszínház út. 8., Hungary \\ *Corresponding Author: mucsi.andras@bgk.uni-obuda.hu
}

Copyright $@ 2013$ Horizon Research Publishing All rights reserved.

\begin{abstract}
This paper deals with the effect of novel gripping systems developed for tensile testing on the stress distribution inside the test piece. The uniformity of the stress distribution plays a decisive role in measuring the upper yield strength and creep behavior of materials. In this study two modified versions of a recently developed gripping system are introduced and tested together with the original version. The tests consist of measuring the bending stress/axial stress ration during elastic loading of the test piece. The bending stress/average stress ratio was measured using a special strain gauge mounted test piece, which was loaded by elastic tension. The results show that the gripping systems provide the self-alignment of the test piece at the beginning of the loading; therefore they can ensure almost true uniaxial conditions for tensile testing. The average bending stress/axial stress ratio is found to be just $1-2 \%$, so, the gripping systems can provide the accurate measurement of upper yield strength and creep curves of materials.
\end{abstract}

Keywords Tensile Test, Gripping System, Stress Distribution, Strain Gauge

\section{Introduction}

The strength-strain relationships and creep properties of engineering materials play a general role in industrial practice and in engineering design. The gripping system used for clamping the specimen determines the stress distribution inside the test piece; therefore it strongly influences the value of upper yield strength and the creep behavior of metallic materials [1-7]. In general case, the uncertainties come from the initial misalignment and non-axial loading of the test piece during the elastic region of the tests, so the errors are mainly caused by the grips used for tensile testing $[7,8]$. A detailed description about the generally used gripping systems can be found in the comprehensive study of Davis [7].

Gripping systems affect the stress distribution inside the test piece and in an indirect manner they largely influence the upper yield strength as well $[3-5,8]$. The effect of a gripping system on the stress distribution inside the test piece can be measured by the widely used strain gauge technique [2, 9-11], neutron diffraction [12] and interferometry [13].

Gray and McCombe [2] studied the effect of wedge and screw grips on the stress distribution in round specimens. They used strain gauges mounted onto the surface of the test piece and obtained that the grips could cause even $80 \%$ bending stress/average stress ratio. Sun [3] and Hutchinson [4] used inhomogeneously annealed steel wires to avoid yielding at the grips: their specimen had larger strength near the grips and lower strength in the center of the specimen. Due to this special test piece the yielding occurred in the center region of the test pieces, which was hypothetically under uniaxial tension.

In order to avoid the errors caused by the conventional grips, a novel gripping system was developed and published in an earlier study [8]. It seems to be suitable for accurate measurement of upper yield strength of low carbon steels; moreover it could be applied for creep tests as well.

The aim of the recent work is to introduce two modified types of the original gripping system and to prove their suitability for uniaxial tensioning. A more detailed analysis is necessary for understanding the facts influencing the stress distribution inside the test piece, which is the other purpose of this study.

\section{Methods}

\subsection{Gripping Systems Used}

Two modified versions of the original gripping system were developed to investigate the stress distribution inside the test piece. The effect of bearing type is also studied. The original gripping system is shown in Figure 1. a. The first modification has been performed on the position of the bearings. In Version A (Figure 1. b.), one pair of the bearings was replaced into the same horizontal position as the other pair of bearings were. In this way a simple spider was created.

The second modification was performed on the type of the 
bearings: the deep groove ball bearings applied in Version A were replaced by sliding bearings made of $\mathrm{Cu}-14 \% \mathrm{Sn}$ bronze (see Figure 1. c.). The specimen was attached to the gripping systems using the same high strength glue fortification technique as in Ref. [8].
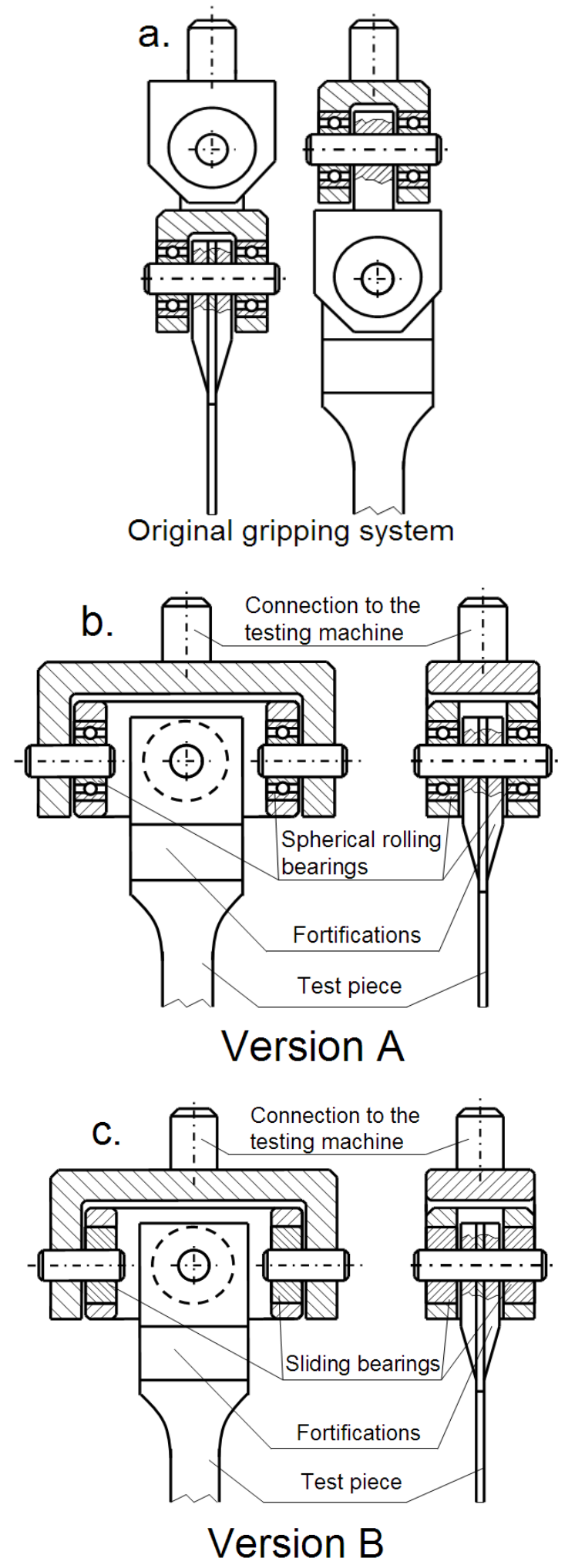

Figure 1. Gripping systems tested in this study. Original version (a.) [8], modified Version A (b.), and modified Version B (c.)

\subsection{The Special Test Piece}

The stress distribution inside the samples was measured using a special rectangular tensile test piece. In order to measure the bending stress arising in the test piece, strain gauges were mounted onto it according to Figure 2. The center of the strain gauges was at distance of $1.5 \mathrm{~mm}$ from the border of the specimen. The bending stress was measured in the direction of larger secondary moment of inertia (in the width direction of the rectangular test piece).

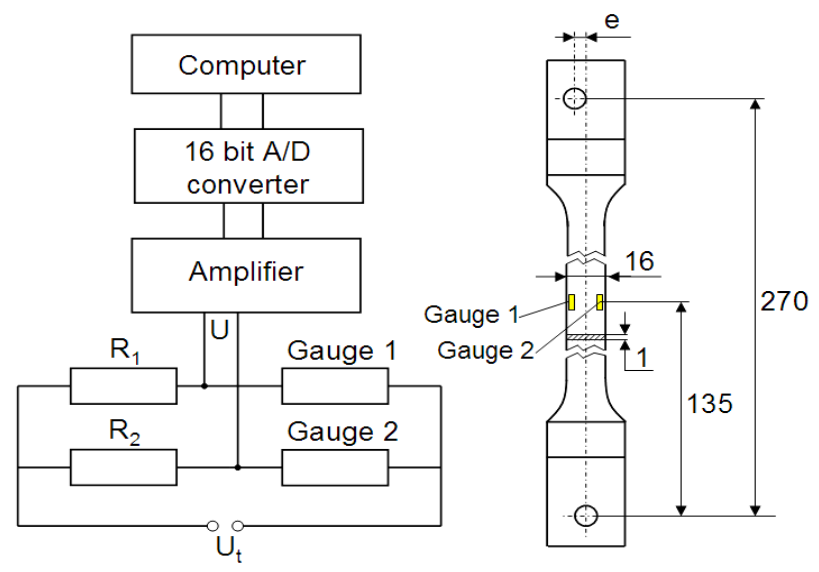

Figure 2. The special tensile test piece used for measuring the bending stress during quasi-axial loading, and the electronic bridge circuit for conditioning the signal of the strain gauges

The strain gauges are connected to the bridge according to Figure 2.: the difference between the tensile stress at the position of strain gauges can be measured with this set up. For supplying the bridge circuit $\mathrm{Ut}=5 \mathrm{~V}$ was used. In order to avoid the errors caused by changing temperature, the complementary resistances $R_{1}$ and $R_{2}$ were the same types of strain gauges as Gauge 1 and 2 . The complementary gauges were placed near Gauge 1 and 2 .

The special test piece was calibrated according to Figure 3. The test piece was placed onto knife-edges through the fortification's holes in horizontal position, which provides free rotation of the test piece due to loading by standard masses. It is obvious that low friction support (such as knife-edge) should be applied for calibration procedure to avoid reaction moments.

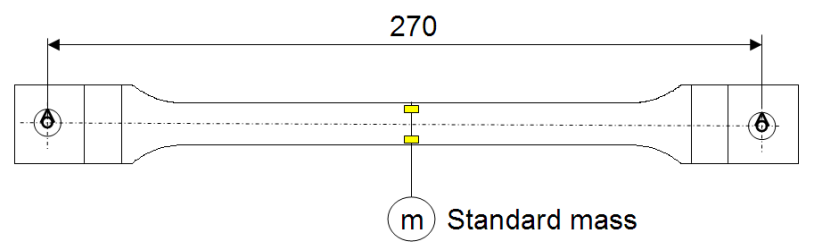

Figure 3. Calibration procedure of the special test piece

The bending stress $(\sigma b$, ) arising from the elastic loading of the specimen with standards according to Figure 3. can be calculated as:

$$
\sigma_{b}=\frac{M_{b}}{I} \cdot p
$$


where $\mathrm{Mb}$ is the bending moment, $\mathrm{p}$ is the distance of gauges from neutral line and I is the secondary moment of inertia in width direction.

The calibration procedure consists of loading the test piece by different masses and measuring voltage $U$ (see Figure 2.).

A very strong linear correlation $(\mathrm{R} 2=0.9994)$ between the bending stress and voltage $U$ was obtained with slope of $57.05 \mathrm{MPa} / \mathrm{V}$. Using this calibration constant the bending stress can be calculated directly from the voltage generated by the strain gauges.

The eccentricity (see Figure 2.) of the special test piece was measured using a Mitutoyo PJ-H3000F profile projector and its value found to be $\mathrm{e}=0.025 \mathrm{~mm}$.

For measuring the bending stress/axial stress ratio 100 axial loading cycles were performed with each gripping system. A loading cycle consists of loading elastically the special test piece with axial stress between 50 and $110 \mathrm{MPa}$ and measuring voltage U. From the measurements the bending stress/axial stress ratio was calculated for each loading cycle.

Preliminary tensile tests show that the yield strength of the material of the special test piece is found to be about $\mathrm{ReL}=245 \pm 7 \mathrm{MPa}$ according to ISO-6892 [14]. It means that the special test piece was loaded only elastically and plastic deformation did not affect the measurements. The experiments were performed using a TTM-100 type electromechanical tensile testing machine.

\section{Results and discussion}

The results show, that the average bending stress/axial stress ratio is just $1-2 \%$ by all types of gripping systems. The frequency of given bending stress/average stress ratios have been evaluated for each gripping system and is shown in Figure 4.

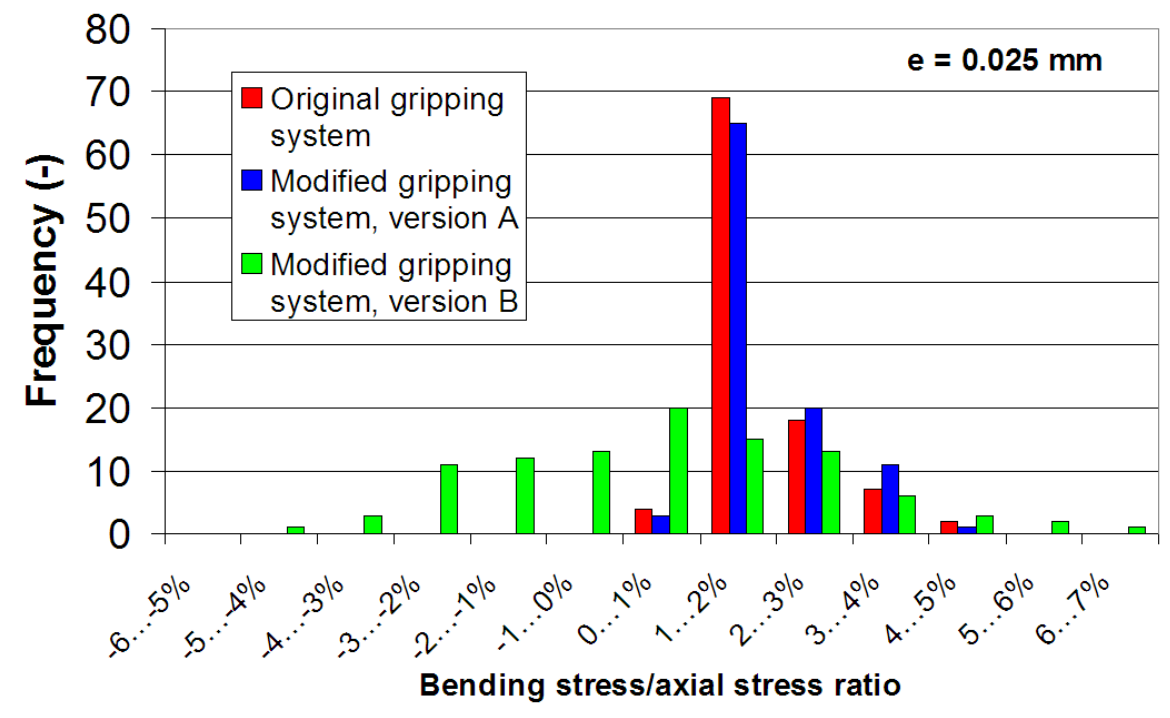

Figure 4. Frequency of bending stress/axial stress ratio using different gripping systems

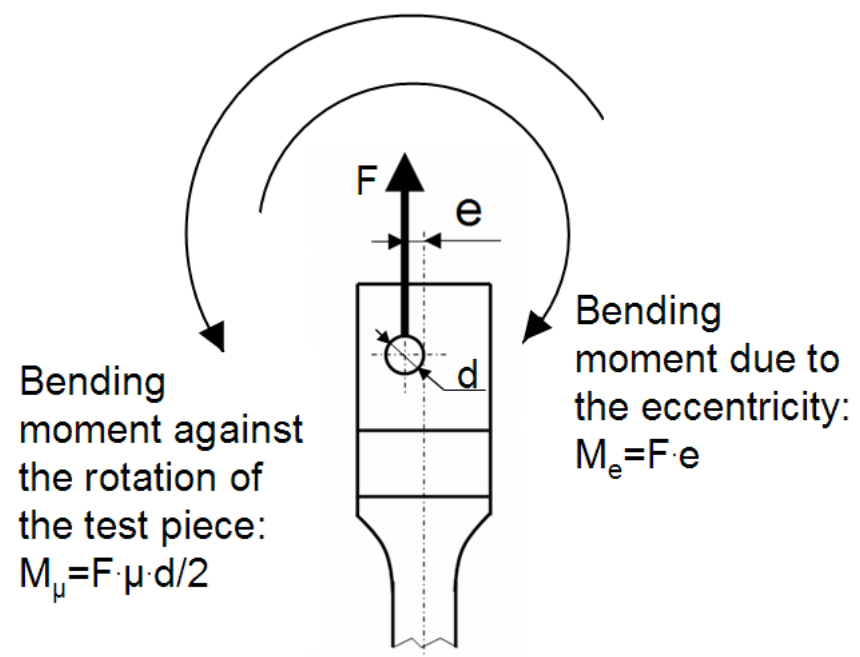

Figure 5. Effects influencing the bending stress 
As it is revealed in Figure 4. the gripping systems provide almost true uniaxial conditions. The original gripping system ensure practically the same frequency at all bending stress/average stress ratio as the Version $\mathrm{A}$, from which it is concluded that the position of bearings is not dominant. In spite of the narrow distribution obtained by the original and Version A the gripping system with sliding bearings (Version B) shows a wider frequency chart, moreover in this case the bending can occur in the opposite direction as it is expected from the eccentricity. This fact can be explained by analyzing the effects influencing the bending stress. The moments arising due to the eccentric loading is represented in Figure 5.

The eccentric loading causes a bending moment $\mathrm{Me}=\mathrm{F}$. e, which tries to rotate the specimen clockwise according to Figure 5. The friction of the bearings tries to inhibit the rotation, therefore a reaction moment $M \mu=F \cdot \mu \cdot d / 2$ appears. The larger the friction in the bearings, the larger the bending moment against the rotation and as a result the effective eccentricity could decrease. This is the reason that the average of the 100 bending stress/average stress ratio is smaller by sliding bearings (Version B) than by rolling bearings (see Figure 4.).

The wider frequency chart of Version B can be explained by the initial self-aligning behavior of the gripping systems. If a perfectly symmetrical test piece $(\mathrm{e}=0 \mathrm{~mm})$ is loaded elastically by tensioning it is not sure that the eccentricity will be equal to zero. The loading force can act everywhere inside the spatial friction cone, therefore the initial eccentricity can be estimated as [8]:

$$
\mathrm{e}_{\mathrm{i}}=\mu \cdot \mathrm{d}
$$

where $\mu$ is the coefficient of friction and $d$ is the inner diameter of the bearing. The coefficient of friction is considerably smaller by rolling bearings $(\mu=0.001-0.005)$ [15] than by sliding bearings $(\mu=0.05-0.1)$; therefore the initial eccentricity and thus the initial misalignment of the test piece must be much larger by sliding bearings. Because of the larger initial eccentricity of the gripping system equipped by sliding bearings (Version B), it exhibits a wider frequency distribution in bending stress/average stress ratio (see Figure 4.).

In spite of the larger errors caused by applying the sliding bearings in Version B, it has some advantages as well. Sliding bearings can bear much larger loading forces than spherical rolling bearings; moreover their simplicity and low cost offer more reliable functioning.

\section{Conclusions}

In this study two modified and the original versions of a recently developed gripping system for tensile testing were investigated. The bending stress/axial stress ratio was measured using a special test piece mounted with strain gauges. On the basis of the experimental study outlined in the recent work the following conclusions can be drawn:
1. The gripping systems introduced in this study provide almost true uniaxial conditions for tensile tests. The average bending stress/axial stress ratio in the special test piece is found to be lower than $2 \%$ at loading eccentricity e $=0.025$ $\mathrm{mm}$.

2. The position of the rolling bearings in the new gripping system does not play a dominant role in the bending stress/average stress ratio.

3. The gripping system equipped with sliding bearing provides a slightly lower average bending stress/axial stress ratio, which is caused by the reaction moment due to the friction in the bearings.

4. The gripping system equipped with sliding bearings exhibits much wider frequency distribution for bending stress/axial stress ratio, which is considered as the result of the initial self-aligning behavior of the gripping system.

\section{Acknowledgements}

The Project was supported through the assistance of the European Union, with the co-financing of the European Social Fund (TÁMOP-4.2.1.B-11/2/KMR-2011-0001). The author is also indebted to Gedeon Richter Talentum Foundation for its financial support.

\section{REFERENCES}

[1] C. Grant, Axiality of loading in the tensile test, The Journal of Strain Analysis for Engineering Design, Vol.7, No. 4, 261-265. 1972.

[2] T.G.F. Gray, A. McCombe, Influence of specimen dimension and grip in tensile testing steel to EN 10 002, J. Iron Steel Making Vol.19, No. 5, 405-409., 1992.

[3] Hong-Bing Sun, Yuya Kaneda, Masanobu Ohmori, Fusahito Yoshida, Effect of stress concentration on upper yield point in mild steel, Materials Transactions, Vol.47, No.1, 96-100., 2006.

[4] M.M. Hutchinson, High upper yield point in mild steel, J. Iron Steel Inst., Vol.186, No. 8, 431-432., 1957.

[5] J.G. Docherty, F.W. Thorne, The phenomenon of tensile yield in mild steel and iron, Engineering, Vol.132, No. 9, 295-297., 1931.

[6] I. N. Webb, A System for the Axial Loading of Creep Specimens, Research report, Ministry of Defence Aeronautical Research Council, London, 1977.

[7] J.R. Davis, Tensile Testing, ASM International, USA, 2004.

[8] A. Mucsi, Effect of gripping system on the measured upper yield strength estimated by tensile tests, Measurement, Vol.46, No. 5, 1663-1670., 2013.

[9] J. Bressers, ed. A code of practice for the measurement of misalignment induced bending in uniaxially loaded tension-compression tests pieces, Joint Research Centre, Institute for Energy, Petten, 1995. 
[10] SA Faghidian, Dev Goudar, GH Farrahi, David J Smith. Measurement, analysis and reconstruction of residual stresses, The Journal of Strain Analysis for Engineering Design, Vol.47, No.4, 254-264. 2012.

[11] A. Kumar, S. K. Chaturvedi, V.Chaturvedi, R. C. Yadaw, Design Studies and Optimization of Position of Strain Gauge, International Journal of Scientific \& Engineering Research, Vol.3, No.10, 1-4., 2012.

[12] H. E. Coules, L. D. Cozzolino, P.Colegrove, S. Ganguly, S. Wen, T. Pirling, Residual strain measurement for arc welding and localised high-pressure rolling using resistance strain gauges and neutron diffraction, The Journal of Strain Analysis for Engineering Design, Vol. 47, No.8, 576-586., 2012.

[13] T. Tjhung, K. Li, Measurement of in-plane residual stresses varying with depth by the interferometric strain/slope rosette and incremental hole-drilling. J. Engng Mater. Technol, Vol. 125, No.2, 153-162., 2003.

[14] ISO 6892-1:2009 Metallic materials-Tensile testing at ambient temperature.

[15] SKF-General Catalogue, Germany, 2003 